\title{
Egyptianising Politics/Politicising Egyptians: An analysis of political jokes
}

\author{
Dalia E. Hammoud, \\ Department of English, Faculty of Education, Alexandria University, Egypt
}

\begin{abstract}
In Egypt, jokes are widely used as venues for ridicule and criticism of political leaders, social conditions, or taboos. The power of such humour lies in the creation of a sense of absurdity surrounding the status quo. The multitude of jokes which appear and circulate is evidence of the importance of the present choice. Moreover, both the significance and scope of the study of humour are reflected in the interdisciplinary nature of the field which draws from psychology, art sociology and literature. The main objective of the paper is to examine one-line Arabic political jokes exchanged on Facebook after the January 25 Revolution within the duration of three months, starting November 2011 and ending January 2012. One hundred jokes belonging to two groups, namely spontaneous and professional jokes, were selected at random. These were analysed according to the General Theory of Verbal Humour by Raskin and Attardo (1991). The proposed hypothesis should prove that there are far more differences between the two sets of jokes, while performing similar functions.
\end{abstract}

Keywords: humour, political humour, jokes, Arab/Egyptian humour, interdisciplinary

\section{INTODUCTION}

"Deprived of the channels for free discussion, criticism and self expression, the citizen is left with nothing but escapism. The skilled and qualified do it physically by emigration, the religious by resorting to fundamentalism, ... and witty by laughing " (Kishtainy 1985: 8). This quote simply summarises the situation in Egypt which "is the unrivalled home of Arab humour....[One] can hardly think of any people who are so engrossed in humour and treat life like a laughing matter, as the Egyptians "(145). A way to keep people going and bear the pressures of life is to conjure up endless jokes as a form of oral nonviolent resistance that is difficult for any regime to counteract by arresting, imprisoning or executing. They are used as tools for mockery and criticism of political leaders, their policies, and economic and political conditions. To Kishtainy (1985) "jokes and jibes [are] more powerful than bullets...[and might be]...the secret behind the Egyptians' knack of survival " (145), and this bears some truth.

Jokes about rulers have been part of our life for ages. Pharaohs' palaces, temples and papyrus scrolls have evidence of political jokes records. Centuries later, the joke was the devastating secret weapon used by Egyptians against the invaders and occupants, exciting their panic and fear.

Focusing on the modern era, the three successive military Egyptian presidents would suffice as proof. Despite their varied achievements, many parties and individuals opposed them. One way of doing so was telling jokes. In Nasser's Egypt, jokes often criticised the secret police and the absence of freedom of expression. When Sadat took over, they were cracked about the government, his clashes with the Muslim Brotherhood and the Church, and his personal life. As for the three decades of Mubarak's rule, thousands of jokes varying in manner and matter were directed at him personally and his policy. Finally, such jokes function as a barometer of public opinion towards the government.

The January 25 Revolution, known as the 'Laughing Revolution', also adhered to that prominent cultural characteristic. On its outbreak, numerous jokes circulated through text messages and Twitter, sweeping Facebook. This dark sense of humour continues to play an essential role in our Egyptian society, being used as a reflection of the people's opinion, their swaying feelings and moods, their psychological and mental state during and after the revolution. Undeniably, jokes offer us comic relief coated with tinges of bitterness.

Outstanding results have been reached in the long history of research on humour and jokes, yet a few deal with the ledger of Arabic political humour. The present paper aims, therefore, at filling this gap by examining Egyptian Arabic jokes. The hypothesis proposes a clear difference between two standards of joke shaping, based on a linguistic comparison, leading to highlighting typical Egyptian elements constituting the jokes and pointing out their functions. Such an approach will directly help answer the proposed research questions.

1) Based on the General Theory of Verbal Humour (GTVH), are there differences between spontaneous and professional jokes (explained in Sample of the Study)? If so, what are they?

2) Do these sets of jokes differ in function, based on Raskin's (1985) classification? ${ }^{1}$ 


\subsection{Sample of the Study}

The data collected is diverse in respect to representing two sets of verbal humour. 100 one-liner jokes were gathered from Facebook. 50 were jokes exchanged by 'average', 'standard' people known to the researcher (i.e., adult, reasonably educated, mainstream culture, etc), referred to throughout the research as spontaneous jokes. The other 50 were posted by Galal Ameir on his personal account, commenting on the events taking place in the country. He is a satirical writer, whose jokes are a unique literary genre, displaying complexity of thought and depth of ideas. Such jokes are referred to here as professional jokes. ${ }^{2}$

\subsection{Scope of the Study}

A number of factors influenced the choice of the sample. First, jokes were collected during a period of 3 months (November 2011 till January 2012) which was full of events. Starting November $19^{\text {th }}$., various public squares witnessed severe clashes between the police and the civilians, resulting in the death and injury of hundreds of people. Despite this tragic situation, poking fun at life, through exchanging jokes, continued.

The following parliamentary elections triggered dozens of jokes. The Islamic parties, though always being banned and oppressed for decades, were competing in the elections. To the surprise and shock of every one, seventy per-cent of parliamentary seats were won by Muslim Brotherhood (MB). People then started composing jokes resisting the rise of such 'extremism', whereas the highly educated liberals just attended talk shows expressing their fears. The third event was in January 2012 with the celebration of the first anniversary of the Revolution.

Another limitation was relying on Facebook as the only source of the jokes (leaving Twitter and SMS out). It has been considered one of the main tools that helped in mobilising and organising the protests at the beginning of the revolution because the old regime had little control over it and underestimated its influential power.

The last limitation was analysing one-liners, and excluding narrative jokes, proverbial phrases, knockknock jokes, and riddles. One-liners are jokes delivered usually in single relatively short precise sentences, thus characterised by certain features. Other than the simple syntactic structure, rhetorical devices (e.g. rhyme, pun and alliteration) are skillfully used, not only to convey the intended message, but also to attract the reader. The internal structure of the one-liner joke has two main components, namely "build- up" (or "set-up") and the "punch line". The former constitutes the body of the joke, which introduces and presents the orientation of the action. Meanwhile, the latter concludes the joke through a surprising unexpected twist, which changes the meaning of the entire sentence. As Sorea's (2007) confirms "the humourous effect comes from the listener's realization and acceptance that their initial assumptions have been unsubstantiated and misleading" (74).

\section{REVIEW OF RELATED LITERATURE}

Humour is a basic form of human activity and cannot be bracketed into a unitary function. According to Krichtafovitch (2006), it is an inborn quality that is necessary for the survival and development of human beings. Humor and particularly jokes have been dealt with by various linguists and psychoanalysts such as Freud (1960), Hempelmann (2007), and Norrick (2009). Freud's Jokes and their Relation to the Unconscious, as Billig (2002) claims, is itself a product of Freud's personal interest in humor where the jokes result from discrimination. In Freud's analysis, repression is the real cause for the relief taking shape in the form of a joke, for usually there is a fundamental conflict between the demands of a social life and personal desires. Repression forces need to return in disguise and haunt man.

To Freud, all jokes are purposeful, including hostile and obscene ones. Aggressive jokes that target social superiors mock and downgrade the authority; "by making our enemy small, inferior, despicable or comic, we achieve in a roundabout way the enjoyment of overcoming him" (103). Shehata (1992) attributes political jokes, which are the focus of the present study, to the hostile type since its purpose is aggressiveness, satire or defense.

\subsection{Psychological and Social Functions of Selected Jokes}

Humour is a powerful social tool that eases tension, removes barriers among groups and blurs any differences. In addition, telling a joke, like any other action, may reflect a person's unconscious desires and satisfy his/her psychological needs. Indeed, it creates "new perspectives to cope with otherwise unbearable environments or circumstances" (Force 2010: para.3).

Political humour is a case in point. According to Raskin (1985), political jokes are divided into two classes - denigration jokes and exposure jokes. Under the first class come scripts of denigration of a political figure, political groups or institutions, political slogans or ideas. Yet those scripts of the other class are those of exposure of national traits, of political repression, of shortages and of specific political situations. 
Based on much research, jokes have more functions. The renowned one, yet quite controversial, is the subversive function which regards political humour as a form of protest against oppression and corruption, seeking political and social change as an outcome. Such a purpose has been reiterated in many studies focusing on Arab political humour, for instance Kishtainy (1985), Fathi (1991), and Kanaana (1995). To them, the joke is "cathartic as it allows people to temporarily overcome their oppressors, to momentarily triumph by ridiculing and criticizing those whom they otherwise would not have been able to ridicule and criticize... [It is] as a 'safety-valve', relieving the pressures and anxiety of political oppression" (Shehata 1992: 76).

Moreover, in relief theories, laughter is regarded as the discharge of nervous energy. Provine (2000) argues that laughter is deployed as a tool for tension relief, echoing Freud, who describes jokes as a kind of psychological release valve that helps prevent the pressure of repression from becoming too great. In addition, Lorenz (2002) says that "most jokes provoke laughter by building up a tension which is then suddenly and unexpectedly exploded" (173).

Other studies claim that the function of political humour is supportive as it indirectly upholds the existing regimes (Billig 2005). Furthermore, Badarneh (2011) asserts that "political jokes only offer a moment for disturbing the discourse of the regime.... [and provide] a temporary alternative framework to the regime's policies and actions" (325).

In the Egyptian society, other than being a coping mechanism, humour has more innovative purposes. According to Salem and Taira (2012), it has been "one of the most important weapons used to sustain Egypt's revolution" (208) in its difficult and tragic moments. It also has a didactic function, being used by the activists to clarify and simplify the demands and aspirations of the revolution (204). Yet the outstanding purpose of jokes for Egyptians is creating a sense of solidarity among people in times of hardship (Harutyunyan 2012). This is greatly evident in many of the spontaneous jokes in which the protestors are positioned as one front against SCAF (the Supreme Council of the Armed Forces). Similarly, in professional jokes, Egyptians are described as second degree citizens through the eyes of the state. This psychological and social function is the main commonality between the two sets of jokes analysed and is one of the core reasons behind their choice.

Verbal humour, being a major component of this paper, necessitates an examination of the theories related to it. Generally, theories of humour are often grouped into three broad categories: superiority theories, relief theories, and incongruity theories. All these complement one another as they orient their studies towards humour from different angels depending on the aspects they consider more fundamental. However, for the present study, the focus is on the two most commonly applied theories: Raskin's (1985) Script-Based Semantic Theory of Humour (SSTH), and Attardo and Raskin's (1991) General Theory of Verbal Humour (GTVH).

\subsection{Script-based Semantic Theory of Humour (SSTH)}

(SSTH) is designed to be neutral with respect to the broad groups of humour theories. As the name states, it is a script-based theory. A script "is an enriched, structured chunk of semantic information, associated with word meaning and evoked by specific words" (99). These scripts can be manifested as oppositions between the 1) actual and non-actual situation, 2) expected and unexpected one, 3) possible and impossible situation (Krikmann 2006: 32). Hence a text is considered a joke, if a second script is found, both opposite in meaning and unexpected.

\subsection{General Theory of Verbal Humour (GTVH)}

In 1991, Attardo and Raskin revised the above mentioned theory for being limited to jokes and working only on the semantic level. Thus they proposed GTVH. According to Attardo (1994), it is a linguistic theory that "is supposed to account, in principle, for any type of text" (222), in addition to explaining the similarities between jokes. Six knowledge resources (KR), which represent parameters regarding joke similarities, achieve this. When generating a joke, other than script opposition (SO), five more KRs have to be considered, namely: logical mechanism (LM), target (TA), narrative strategy (NS), language (LA), and situation (SI). While (SO, SI, TA) are related to content, (LM, NS, LA) are related to form (Hempelmann and Ruch 2005). These KRs are defined as follows:

2.3.1. Language (LA). "It includes all the choices at the phonetic, phonologic, morphophonemic, morphologic, lexis, syntactic, semantic, and pragmatic levels of language structure that the speaker is still free to make, given that everything else in the joke is already given and cannot be tinkered with " (Attardo and Raskin 1991: 298).

2.3.2. Narrative Strategy (NS). It is the rhetorical structure of the text, or the genre or micro-genre of the joke (300). Any joke has to be in a narrative form, whether a simple one, a dialogue, or a (pseudo-) riddle. However, other non-narrative humour exists as it does not tell a story.

2.3.3. Target (TA). This is the butt of the joke, describing the person or group of persons from whom humourous behaviour is expected and at whom the joke is aimed. They are often stereotypical, which makes them liable to 
be scorned and attacked. It is the only optional KR among the six, since there are jokes that "do not ridicule someone or something" (Attardo 2001: 24).

2.3.4. Situation (SI). This could be the props, which include the objects, the persons playing roles in the jokes, location, activities, etc. These textual materials are not necessarily funny. SI includes cultural-specific references. As Attardo (2001) states, this KR is not unique to jokes, but it is a function shared by all humorous and non-humorous texts.

2.3.5. Logical Mechanism (LM). It is this KR that reveals the lack of commitment to the truth in the context of the text. Consequently, laughter results from the juxtaposition between a primary interpretation of the situation and the alternative one introduced at the end of a joke. LM accounts for the way in which the two scripts in the joke are brought together in an unexpected way.

2.3.6. Script Opposition (SO). This parameter was first presented in the SSTH. The main claim of SSTH is that the text is always fully or partly compatible with two scripts, opposing each other in a special way. In other words, as Attardo and Raskin emphasise (1991: 308), the text of the joke is made deliberately ambiguous. The punch line prompts the switch from one script to the other by making the joke recipient backtracks, realising that another meaning could be grasped from the very beginning.

Consequently, the GTVH needs revision. A category, such as 'Language LA', is general and imprecise, so it is subcategorised later (see Procedure) into 7 specific elements, namely: lexical ambiguity, use of synonyms and antonyms, repetition, figurative language, language style used, semantic classes and satire. Logical Mechanism (LM) is omitted in the present analysis as it is the most problematic KR and can be considered an 'artefact' (Krikmann, 2006). These alterations have been done to compensate for the vagueness of Attardo and Raskin's (1991) model and to open an avenue for making the model applicable to culturally bound jokes, especially Egyptian jokes, which have radically changed since 2011 with the outbreak of the Revolution and the Arab Spring.

\section{Modified Model of Joke Text Analysis}

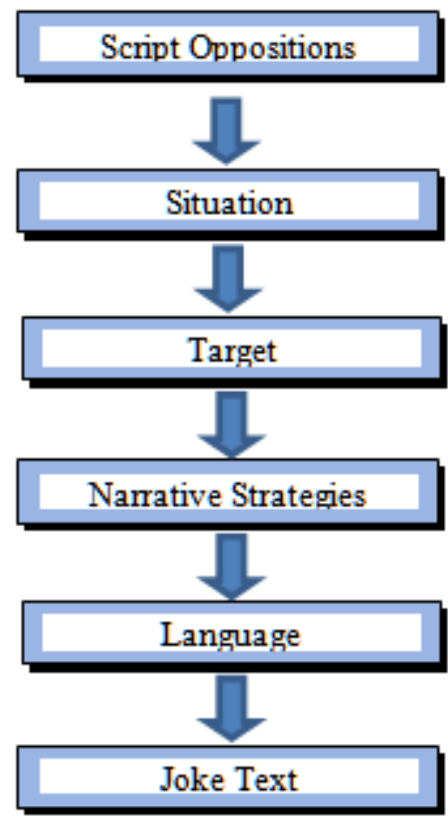

\section{PROCEDURE}

The following modified figure of Attardo and Raskin's model reveals that a top-bottom type of analysis is applied when handling the sample of the study. "An important aspect of the GTVH is the hierarchal organisation of the KRs. The basic principle is that a certain KR probably will determine or will be determined by another KR. The hierarchical organisation of KRs is: SO, (LM), SI, TA, LA, NS, LA, organised from less similar and less determined to more similar and more determined" (Mulder \&. Nijholt, 2002: 12).

\section{DATA ANALYSIS AND DISCUSSION} Resources.

Applying the GTVH to the selected jokes led to these outcomes regarding the five different Knowledge 


\subsection{Script Opposition}

Examining the given data shows that ending with a sudden opposition with the recipients' expectations is a common factor amongst all. For instance, in this joke

\section{Palak Gi:d ilṣãwrã // hãa:dir hạidha}

They said: 'anniversary' of the Revolution and I replied: Okay, I'll repeat it.

in script 1, words like 'celebration', 'feast', 'happiness' come to one's mind. Yet script 2 presents ideas like 'repetition', 'acceptance', and 'submission'. Such an opposition in scripts creates a sense of humour.

In general, what happened after the revolution was the reversal of what was anticipated. Egyptians expected political and economic stability which is definitely not the case now (2014). Stranded in a grey stage, they have no clear idea of what should be done. They thought that the revolution would bring about a magnitude of change in terms of justice and equality which has not been the case either. Unfortunately, after the revolution, people feel the real meaning of oppression in all fields because of the hegemony of those in authority. There has been no freedom of speech, no social justice, no bread, no human rights; nothing of the revolutionaries' demands has been achieved. To sum up, the oppressive regime the Egyptians fought against during the 18 days of the revolution had not been toppled down. Only its tyrant had been changed from Mubarak to SCAF.

\subsection{Situation}

The main topic of all the jokes is the January 25 Revolution, but, in most cases, there are other subsidiary topics; first, the Egyptians' life has become worthless. Second, both Muslims and Christians are being killed. Third, SCAF can never be trusted. Fourth, Muslim Brotherhoods (MB) and Salafists will change the Egyptian identity. Moreover, the revolutionaries have been fooled and deceived, and at the same time, are blamed for that. The participants in the jokes are the narrators, including all Egyptians. However, the messages are addressed either to SCAF (in many cases Field Marshall Tantawy), MB, the regime, or the Egyptians themselves.

4.2.1. Egyptian Culture. Humour exists in every culture and epoch and differs from one culture to another. Indeed, "a joke packs cultural intertextuality into one short sentence" (Salem and Taira 2012: 195). The selected jokes under study include words or pieces of information that pertain only to Egyptian cultural elements that can hardly be understood outside their cultural-bound context, for instance:

Pąlanat dãr-iliifta:? almãsriyyah / Panna yawm Parãbiৎ waļifri:n min yana:yir howal-mutamim lifahr yana:yir / wi?nna- lãrba\{a:? alqãdim gurrat fahr fibrãyir / yuSiduhu-llã:hu Salayna bi-Palf xeyr ${ }^{2}$

Egyptian Fatwa House announced that Tuesday the $24^{\text {th }}$ of January is the last day of the month and that Wednesday is the beginning of February. May God grant us many happy returns. ${ }^{3}$

To find the joke funny, one needs to know that before the holy month of Ramadan, Egyptians, like all Muslims in the world, wait for the announcement made on TV whether to fast or abstain from fasting for one more day based on the Islamic lunar calendar. The Mufti uses exactly the above words, except for the dates. In this spontaneous joke, it is believed that SCAF is likely to make such an announcement, so that people forget about celebrating the first anniversary of the Revolution, with all its consecutive events.

The coming joke highlights an influential process in the future of any person just finishing school. Students passing secondary school have to sit for the 'Thanaweyya Amma' exams and their results define their career. Central Management Offices (maktab altanse: $q$ ) are then responsible for assigning students to faculties, according to their preferences and grades. Similarly, when the Egyptians revolted, they wanted a peaceful change believing then that either Tunisian or Libyan examples were ideal models to follow at the time. However, they got the Syrian scenario of bloodshed. The two situations were automatically related in people's minds believing them the worst option:

Pif-SaSbi-lmașri katab raġba Pu:la tu:nis / raġba tanya Libya / wi-ltansi:P / gabloh surya

Egyptians chose Tunisia as a first choice, Libya as a second, yet the central management body chose Syria.

In the next example, if the recipient does not know places such as Giza, Zamalek, Smouha, and the two most famous rival football teams in Egypt, Al-Ahly and Zamalek, s/he will not get the jest that suggests confusion and disorder:

Pihnna Pãșlan faSb ta:yih / gam Sit-ilqãhirah mawgudah f-ilgi:zah / w-ilna:di-ilahli mawgu:d fi-z zama:lik / wa mada:ris sidi ga:bir mawgu:dah fi-smu:hah / kidah țâbiSi giddan Pin șãwritna nighit fi-tu:nis.

Our people are at a loss!! Cairo University is in Giza; Al-Ahly is in Zamalek; Sidi Gaber schools are in Smouha, so it's quite normal that our revolution has succeeded in Tunisia.

Since none of its demands have been fulfilled, people believe that the Revolution has failed, specially that the course of action took a completely different direction from what they had anticipated. Making fun of such an unaccepted outcome, Egyptians are given an excuse, since many foundations, schools, or clubs are located in areas and places that do not bear the same place names. 
Similarly, in the professional jokes, Ameir makes reference to Egyptian culture when he ridicules the passivity of SCAF in dealing with the current problems and exposing political repression. The state would not take action about the chaos going on, like the frequent strikes and road blockades, unless it has something at stake in the fanfare. This is reflected in:

Pinnad-dawlah la tatadexxel Sinda qãt țãri:q-assayyarã:t / Pila liPannaha rubama taku:n bitzif Sari:s

The state does not intervene in road blockades, unless if it is sending a groom off on his wedding.

Reference is made to the Egyptian wedding ceremony. For many, the ceremony has to start with a car parade where the wedding car is decorated with flowers, accompanied by the cars of both families. This procession moves together in the streets, while honking, to announce the event, until they reach the wedding hall.

On December $18^{\text {th }}$, Egypt's oldest research institute caught fire. Until the present moment, the culprit is unknown. Ameir mocks the willingness of the state to frame any person to save its image, to the extent that 'literary' students will be accused of burning the 'Scientific' Academy. In Egypt, secondary school students choose either the scientific or literary section, which gears them to certain faculties at the end. Without that background information, the recipient would not get the humour in such a joke.

len PataSaggeb Piða qã;lu: Pinnal-laði Pãhrãqa almagmaS alSilmi: hum tããäbit ilPadabi:

Would not be surprised if they said that those who burnt the Scientific Academy are the literary students.

In reference to the famous song (Misr tatahadaO San nafsiha) 'Egypt speaks about its glory' by Om Kalthoum, while keeping the original rhythm, Ameir uses the same leading in words, yet changes the endings. His anger and blurred vision lead him to replace highly patriotic words with sarcastic ones revealing his view of the bitter reality of the Egyptian system and its corruption. The original words of the song were:

wãqãfã-lxãlqu / yãnOuru:na gami:San / kayfa Pabni qwa:Sid-almagdi wahdi: / wa-buna:tul-Pahrã:mi fi sa:lifad-dãhri kafawni akkala:m Sindat-tahaddi:

All the people stood in unison watching how I alone build the foundation of my glory, and those who built the pyramids, centuries ago, answered any doubts about my capabilities.

However, Ameir's joke is:

wãqãfã-lxãlqu / yãnOuru:na gami:San / kayfa Pasriq wadaPį-albanki wahdi: / wahuma:tul- Pahra:mi fi saSital؟ãsri xaduni: ilmãtãa:r wi Palu:li Saddi:

All the people stood in unison watching how I steal bank deposits, and those who protect the pyramids, in the middle of the day, took me to the airport and said "pass".

As evident through the above jokes, because of the hardships and disappointments, Egyptians resort to jokes as a way of expressing anger, thus causing a temporary psychological relief. It is also apparent that our historical and cultural background prominently influences our production of jokes, shaping our lives and minds.

\subsection{Target}

The following table summarises the different targets attacked in the two groups of the study.

\begin{tabular}{|c|c|c|}
\hline Types of Jokes & Targets Attacked & Number of Jokes \\
\hline \multirow{3}{*}{ Spontaneous jokes } & MB \& Salafists & 20 \\
& SCAF & 16 \\
& Revolution & 3 \\
\hline \multirow{3}{*}{ Professional jokes } & Mubarak & 3 \\
\hline & Regime & 27 \\
& Regime & 7 \\
& Self-criticism & 5 \\
& Elections & 5 \\
& Human degradation & 4 \\
& Mubarak & 2 \\
\hline
\end{tabular}

According to Badarneh (2011), contemporary Arab political jokes focus on three main themes: economic reforms, democracy, and elections. However, January 25 Revolution politicised Egyptians greatly and even influenced their jokes. Examining the table sheds light on many aspects of the current Egyptian situation at the time. Firstly, only in professional jokes is there 'self-criticism' and 'human degradation', stressing their function as an 'exposure of national traits' of submission and irrationality. It is assumed that education comes with a higher level of awareness of society, the role of the individual in it...etc. Moreover, the more educated a 
person is, the more s/he is exposed to different cultures which influence the way s/he thinks and deals with everyday issues (e.g., human rights, democracy, corruption). All this awareness and exposure force an intellect to look at matters objectively. Consequently, s/he does not blame others for the existing problems, but only her/himself, unlike the commons who usually condemn others for any mishap. This might be the reason behind such an observation.

Secondly, while spontaneous jokes attack what is often described as the 'Islamic Tide' with its two main components, Muslim Brotherhoods (MB) and the Salafists, professional jokes avoid doing so. On the one hand, the latter group seems to be more cautious, or reserved towards that tide, trying to be detached, neutral and not to pass judgements immediately. On the other hand, different external factors, like media, twitter, Facebook and newspapers, have a significant impact on the common people, shaping their opinion. Hence, the majority are led to react alike to a certain issue. Social Psychologists attribute such a reaction to the mob effect, which has the power to subconsciously change a person's behaviour. Thus, criticising SCAF and MB might be an echo of what is being heard from different sources. In that case, the main function of these specific jokes is the 'denigration of ruling and political groups'.

Thirdly, in scorning SCAF, the spontaneous jokes particularly ridicule the age factor in five jokes. People cannot accept the idea that the 'Revolution of the youth' was taken over by elderly people, who were placed in most of the important governmental positions. Here these jokes tend to expose specific political situations. This issue is explicitly stated in:

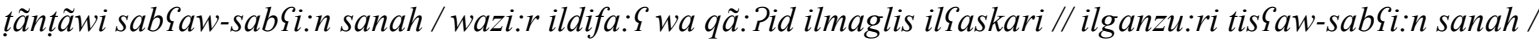
rã?i:s maglis ilwozãrã: // wi Paxi:ran mãnsu:r hasan itne:n-wi-tamani:n sanah / rã?i:s ilmaglis ilistifa:ri: // fiSlenn șãwrit yanayir / hiyya șãwrit il Sabab tật xamsa-wi-tamani:n

Tantawy, the Minister of Defence and the Chairman of the SCAF, is 77. Ganzouri, the Prime Minister, is 79; and Mansour Hassan, the Chairman of the Advisory Council, is 82. Indeed, January Revolution is a Revolution of youth under 85 .

Tactfully, Ameir mocks the same element, very subtly, making use of homonymy:

mata yatruk gi:l ilfis brisli Palsoltã Pila gi:l ilfis buk

When will Elvis Presley's generation leave the rule to Facebook generation??

In all of the above jokes, laughter is pointed clearly at someone, as it is directed down at 'deformities' and 'imperfections' (here old age) from a position of perceived superiority. Consequently, Gruner (2001) insists that in every humorous situation there must be a winner and a loser: if not, this renders the situation humourless.

\subsection{Narrative Strategies}

These jokes are all one-liners which are unique since they play with and upon words. They are humorous because on the surface, they violate the initial expectations of the listener by shifting to another completely different knowledge frame. Moreover, their microgenres vary from being expository to questionanswer sequences. Mostly Ameir's jokes are expository as seen in:

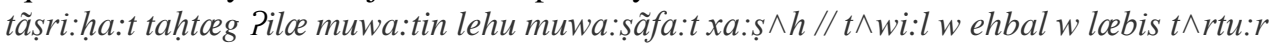
To understand issued statements, in need of a specific kind of citizens: dupes and fools

Hence, to be able to understand the irrationality of the SCAF's statements, citizens have to suspend their reason and wit. This joke functions as a 'denigration of the ruling group'. However, in the spontaneous jokes, question-answer sequences are sometimes used:

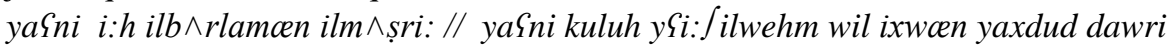

How would you describe the Egyptian parliament? It's when everybody thinks they are going to win seats, but the MB wins them all.

\subsection{Language}

The language is analysed to indicate how the linguistic and rhetorical elements intervene in cohesion to express the humour created in the text. The use of figurative expressions is then identified.

4.5.1. Lexical Ambiguity. Here, humour is derived chiefly from lexical ambiguity which, according to Oaks (1994), is conveyed by "a word with more than one possible meaning in a context" (378). Semantic confusion stems from using various strategies. While 'paronyms' refers to two words that have similar, but non-identical, phonemic representations, 'homonyms' have identical phonemic ones, though unrelated meanings. Another strategy is using 'homographs', where two words are spelt the same.

Many of the jokes can be categorised as 'Wordplay' jokes, depending on words that are similar in sound or spelt differently, but having different meanings. This difference in meaning creates opposition and shatters expectations, so it becomes humorous as evident in Ameir's reliance on the phonological resources of the language in (mulu:k)- 'kings' and (sulu:k) - 'behavior'. 
In Arabic, using homonyms requires a better command of the language compared to using paronyms. Surprisingly, while spontaneous jokes show many cases of homonymy, professional jokes have one. In the former group, when homonyms were used, the jokes could be interpreted only in one way.

Palak Gi:d ilșãwrã // hãa:dir hạidha

They said: 'anniversary' of the Revolution and I replied: Okay, I'll repeat it.

However, when in professional jokes paronyms are used, multiple connotations could be inferred, hence allowing the joke to dwell longer in the listener's mind and leave a deeper effect.

tãrqud aț-tuyu:r Yala bãydãhã lyãfqis / wa yãrqud alhokkam Sala SuSu:bihim litãfțãs

Birds lay on their eggs until they hatch, whereas rulers lay on their people until they perish.

In this example, birds sit on their eggs to protect them until they hatch, thus changing into a better state (chick). In contrast, the rulers in the developing countries stay in power for decades and oppress their people, changing them into a worse state on all levels. Thus the function of such a joke is the 'denigration of political figures'. Another example is:

min-ilta:ri:x Pila-lgoġrãfya..... $\tilde{a}$ đãmit Paltãyã:r Palsalafi: Palsiyasi Pannahu sawfa yãnqul misr mini-lqarnilwahid wallifri:n Pila-ilqarn-ilafriqi:

From history to geography... the glory of the Salafist political ideology lies in the fact that it will transfer Egypt from the $21^{\text {st }}$ century to the Horn of Africa

By playing on the pun in the word (qarn) القرن, which means in Arabic both "century" and "horn ", a humour twist is created. The reader moves from the high expectations of the $21^{\text {st }}$ century with all its progress to the Horn of Africa and what it implies. Ameir accuses the Salafists of transferring Egypt into a much worse state if they were ever to be in control. They will throw Egypt into oblivion and sheer regression. "The Horn of Africa" denotes the region containing the countries of Eritrea, Djibouti, Ethiopia and Somalia. These undeveloped countries have been experiencing many incidents of drought, coupled by conflicts in Somalia that has resulted in the starvation and death of thousands of people, leaving children suffering from malnutrition, a situation that cannot be worse. Certainly, Egyptians succeed in concealing aggression through their manipulation of words.

4.5.2. Use of synonyms \& antonyms. None of the jokes display any use of synonyms. Probably, the structure of the one-liner joke requires the message to be conveyed in the shortest and most precise way, so there is no room for using synonyms. However, when looking for antonyms, a large discrepancy between the two groups (spontaneous versus professional) is evident. Ameir uses them in thirteen cases. In the following joke, he uses opposites four times simultaneously in order to emphasise the amount of corruption the previous president was responsible for, through stressing on several grievances of the Egyptians:

tãrãkana: mubãrãk Sarãya: wiPiktasa: howa // gawSa: wa shabaSa howwa // foqãã̃:? wa Pigitana: howa // mãrda: wa Su:liga howa // wSindama qomna bilӨãwra: l-tãhqi:q ilSadl // tahãaãqa lahu

Mubarak left us naked, while he was dressed, hungry, while he was full, poor, while he became rich, and sick, while he was cured. Yet when the Revolution called for justice, he was the one who got it.

In the spontaneous jokes, antonyms are rarely used to create juxtaposition of ideas, leading to humour, for instance:

sataku:n qãrãrã:t Pat-tayyã:r Pal-Pislami: kel-Pati:// hayfilu iltufahah bitaGit Pãy fo:n / wi- yihottọ balahah If the Islamic Party ever wins, it will replace the apple on iPhone with a date.

The joke teller chooses 'dates' in particular as they are considered a favourite fruit for Muslims, especially in Ramadan.

4.5.3. Repetition. Repetition is one of the frequent techniques in these jokes. It is a very effective means for the recipient to grasp the intended meaning. Other than causing a rhythmic pattern, it serves to exaggerate the situation, stressing humour because of "the tension created by some kind of a series being established" (Berger 1998: 46). This feature is seen in both spontaneous (1) and professional jokes (2), for example:

(1) iș̣ãwwrã hazamit ix-xo:f fi xamsa-wSifri:n yana:yir alfi:n w-hidãfer // wi- hazamit id-daxliyya fi tamanyawGifri:n yanay:ir alfi:n w-hidãfer // wi- hazamit mubãrãk fi hida:fãr fibrãyir alfi:n w-hidãfer // wi hatla:Sib il-maglis il-Saskari fi xamsawSifri:n yana:yir alfi:n witna:fär

The revolution defeated fear on $25^{\text {th }}$. of January 2011, defeated Ministry of Interior Affairs on $28^{\text {th }}$, defeated Mubarak on $11^{\text {th }}$. of February, and will play the finals against the SCAF on $25^{\text {th }}$. of January 2012.

(2) qãbl Piktija:fil-Poksogi:n / kayfa kana yatanaffes an-na:s // wa qãbl Piktifa:f il-Parqã:m wal-PaSda:d/ kayfa kanat takðib alhuku:ma:t

How did people breathe before the discovery of oxygen? How did governments lie before the discovery of figures and numbers? 
4.5.4. Figurative Language. Only in the professional jokes can one encounter some usage of figurative language, such as a simile in:

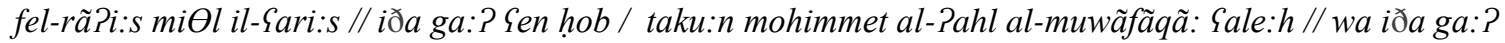

Gen mașlãhãa: / taku:n mohimmet al-\{ãrusã ar-riḍã bih

The president is like a suitor, if he proposed out of love, the parents have to accept him, yet if he was of interest to them, the bride has to accept him.

The simile implies that Egyptians will have to accept the president who is backed by SCAF.

A metaphor is also found in:

xutu:rit maglis illu:rã Panna-lmuwãtin la ya/\{̌r bih // falaysa lahu Payy PãSrã:d

The danger of the Senate House on the citizen is that he does not feel its presence as it has no symptoms.

Here Ameir indirectly likens the Senate House to a dangerous disease whose presence one does not detect as it has no symptoms. He is criticising the uselessness of such an institution.

Furthermore, by just dropping one preposition in another joke, the whole meaning is twisted into a bitter satirical reality, such as:

fi hađihi Pam-mãrhãla // men howa țãbãa:x irrã̃i:s Palaði yãqif fil-mãttbãx / laysa lyațu: lir-rãPi:s / wa la:kin lyațu: lana ir-rã̃i:s / Oumma yoqãdimoh lil-na:s sa:xinnen / laysa lta?kul / wa la:kin ltãbṣum

At this stage, we need to know who the presidency's chef is. The one standing in the kitchen, not to cook for the president but to prepare the president then present him "hot" to the people not to eat, but to hail. ${ }^{3}$

Ameir is subtly and implicitly accusing SCAF of interfering in the elections to force a certain presidential candidate on the Egyptians. He does so through likening SCAF to a chef, who is in complete control of the process, and the president to a dish, which might appeal to the people in appearance, but its taste is according to the chef's will. Unquestionably, the depth in meaning created by Ameir's choice and play with words is much more than that expressed through the spontaneous jokes.

4.5.5. Language Style Used. Professional jokes are in Modern Standard Arabic (MSA), with rare cases of Egyptian Colloquial Arabic (ECA) words often inserted between quotation marks. In contrast, the spontaneous jokes are mostly in ECA and few are in MSA, as colloquialism symbolises "the role that political humor plays in sweeping away, erasing, or at least weakening the boundaries that exist between the ruler and the ruled " (Badarneh 2011: 316). In spite of the discrepancy between Standard and Colloquial Arabic, "it is still important to note that such linguistic-register divergence produces a comic effect" (Salem and Taira 2012: 202).

As examples, joke (1) is a written spontaneous one, illustrating the use of ECA, whereas joke (2) is in MSA, being a professional one.

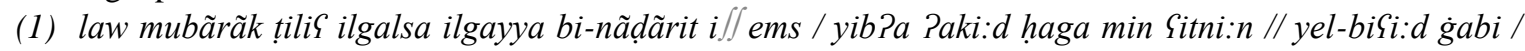
ya biyitha:kim fi-guzur ilbãhãmãz

If Mubarak shows again in court in his sunglasses, it has to be one of two things: either he is stupid or the trial is in the Bahamas

People are making fun of Mubarak for showing up every time in the court room in his sunglasses. They assume that such behaviour is either due to his stupidity or him being trialed in the Bahamas.

(2) tuha:wil Pad-dawla gaSl Palwãðãaif iliktroniyya / lil-qãdãa:P Salal-rãfwã // wi maS ða:lik / ințãðiru: qãri:ben mãws yaftah Paldurg

The State is trying to computerise many jobs to put an end to bribery; however, expect that soon the drawer will open by a mouse click.

Ameir believes that as long as people do not alter their behaviour, things will remain the same despite the states' numerous attempts to improve the country. This is conveyed through the second script where "the drawer will open" (which implies bribery) by a mouse click.

4.5.6. Semantic Classes. On analysing the data, recurring semantic classes emerged significantly in both sets of jokes, namely 'Human-centric vocabulary', 'Negative orientation' and 'Human weakness'. Constant reference is made to human-related situations, as evident in the frequent use of first and third person singular and plural pronouns, 'we' (nahnu) and 'they' (hom). Sometimes, mockery is directed against either the subject himself or his nation; in other incidents, it demoralises the 'enemy', giving us a temporary sense of satisfaction and victory.

All the 100 jokes contain at least a word or two with negative connotations whether nouns, verbs or adjectives, such as 'fall' (yasqot), and 'cheat' (texdaSu). Those "words with negative orientations are potential reflections of the incongruity-based theories of humour" (341). Humour stems from the difference between what the recipient of the joke expects to happen and what actually happens. While the introduction and the main part of the joke might evoke a certain expectation in a certain direction, the revelation of the punch line subverts that expectation. 
Under 'human weakness' are words that describe "events or entities that are often associated with 'weak' human moments" (Mihalcea and Pulman 2007), for instance, 'catastrophe '(musibãh), 'killed' (qãtalu), and 'hungry' (gaw 9 a:). That "kind of vocabulary seems to relate to theories of humour that explain laughter as an effect of frustration or awkward feelings, when we end up laughing 'at ourselves' ” (342).

4.5.7. Satire. Satire is another technique used for ridicule. Unlike the spontaneous jokes, Ameir, in most of the professional ones, is being very satirical, using witty and intense language to ridicule and scorn the regime or even the Egyptian citizens (including himself), resulting in much humour:

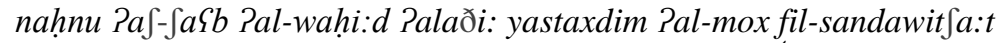

We are the only nation that uses 'brain' in sandwiches. ${ }^{4}$

The writer mocks the Egyptians for eating 'brains', instead of using them, which is a less-than-human activity and which connotes many follies. It is noteworthy that cow's brain is a popular Egyptian meal. In addition, self-criticism is further represented in:

Palhuku:mah laysat mas?u:lah San fãqrana: // nahnu min ilfãqãriyya:t

The government is not responsible for our poverty... We are vertebrates

To Ameir, poverty is an innate quality of Egyptians, so we are destined to be poor as we are destined to be vertebrates. No matter what we do, nothing will change that state, as poverty seems to be biological and not acquired.

\section{CONCLUSION}

In Egypt, jokes play a crucial part in determining who we are, and we, in turn, succeed in personalising and Egyptianising them; they help us overcome the cruelty of life and break the fear barrier. Other than reflecting our feelings, beliefs, problems, culture, and political views, they "create a sense of camaraderie" (Salem and Taira 2012: 192).

The previous analysis has been a case study of some Egyptian political jokes. Through the use of oneliners, Egyptians produced the maximum of humour, dressed up in dark sarcasm, with a minimum number of words, resulting in precision and brevity, which are the soul of wit. As an answer to the first research question and contrary to the proposed hypothesis, many commonalities stem between spontaneous jokes and professional jokes when examined within the frame of the General Theory of Verbal Humour. These similarities seem to be more significant than their differences in regard to the broad Knowledge Resources, whether in situation, narrative strategies, or script opposition. However, the research reveals that humour differs in specific linguistic elements in the professional jokes, like the use of figurative language, antonyms, paronyms, and language style, and also in their functions. Generally, the latter type of jokes ridicule the target in a more objective way, yet with much more cunning cynicism.

In addition, it is evident from the analysis that "with cumulative cultural common knowledge from the present and past, jokes absorb current political and social events and incorporate them into the joke itself" (Salem and Taira 2012: 197). Both types of jokes include words that are culture-dependent, relying on the listener's beliefs and knowledge of paratextual and intertextual narratives surrounding them. In many cases, without such knowledge, the listener will not laugh. Indeed, the interdisciplinary nature of intervention of various elements in the structure of a joke adds to the revealed dimensions in the analysis.

Humor is not always evocative of laughter because it may arouse smiles or smirks; people may smile/laugh because they are uncomfortable or nervous. In Egypt, a joke is sometimes a cry of anger and frustration interrelated with laughter. Dare we say it is far from being a joke? Certainly, for Egyptians, "every joke is a tiny revolution".

\section{APPENDIX}

Key to Transcription System (adapted from Bassiouney, 2009)

First: Consonant sounds specific to Arabic:

A glottal stop, as in /Pumm/; i.e. mother.

/q/ A uvular voiceless plosive, as in /qânu:n/; i.e. law.

/r/ A trill, as in /râgil/; i.e. man.

/x/ A voiceless fricative, as in /xuḍâr/; i.e. vegetables.

$/ \dot{\mathrm{g}} / \quad$ A voiced fricative, as in /gari:b/; i.e. strange.

/h/ I A pharyngeal voiceless fricative, as in $/$ hilm/; i.e. dream.

/§/ A pharyngeal voiced fricative as in / Sarabiyya/; i.e. car. 
Second: The Arabic letter " $"$ " is pronounced as the English letters "sh", i.e. /J/, the letter " " "

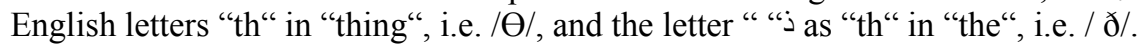

Third: Emphatic consonants, these include:

$/ \mathrm{t} /$

/Ṣ/

/ḍ/

/ẓ/

Fourth: A geminated consonant is indicated by doubling the letter.

Fifth: Short vowels include:

/i/ close front

$/ \mathrm{u} /$ close back rounded

/a/ open back unrounded

Sixth: Long vowels are indicated by adding ( : ) after the letter. These include:

/i:/ e.g. /ti:n/ (i.e. figs)

/u:/ e.g. /su:rah/ (i.e. a photograph)

/a:/ e.g. /sa:ৎah/ (i.e. watch).

/e:/ e.g. /le:h/ (i.e. why?)

/o:/ e.g. /do:1/ (i.e. those).

Seventh: The sound /a:/ as in "father" is replaced by /â/ to be differentiated from the long vowel /a:/ sound used in Arabic.

Eight: A forward slash (/) denotes a short pause, and two slashes (//) a long pause.

\section{NOTES}

1. Such functions will be discussed throughout the paper without being subsumed under a specific section in order to avoid repetition, and also for limitation of space and convenience of reference.

2. It was challenging to choose terms that differentiate between everyday jokes written by 'ordinary', 'standard' people and others by professional satirists like Ameir and yet, be unbiased or not carry any negative connotations. When first 'commoners' versus 'elite' was chosen, other than adding an irrelevant sociolinguistic variable, it implied a sense of superiority. The word 'laymen' was considered offensive and demeaning. The term 'highly educated' in reference to Ameir, meant the exclusion of such people, when dealing with the other group of jokes. Consequently, the researcher decided to categorise the jokes according to their type, not those who wrote them, settling on spontaneous jokes versus professional ones.

3. Though the data used in this research is mainly written, there is still considerable variation within it. It includes both ECA and MSA which are pronounced differently. Consequently, professional jokes are transcribed the way they are 'supposed' to be pronounced, whereas spontaneous ones the way they are actually said.

4. The purpose of the present research is not to capture the humourous aspects of the jokes as much as to linguistically analyse the jokes themselves. Thus the researcher had to introduce the context and explain some cultural elements to help in conveying the message.

\section{REFERENCES}

[1] K. Kishtainy, Arab political humour (London: Quartet, 1985) .

[2] V. Raskin, Semantic mechanisms of humor (Kluwer Academic Publishers, 1985).

[3] D. Sorea, Jokes and the instantiation of conflicting scripts (2007). Retrieved from http://bwpl.unibuc.ro/uploads_ro/753/BWPL_2007_2_Sorea.pdf

I. Krichtafovitch, Humour theory: Formula of laughter ( Outskirts Press, 2006).

[5] S. Freud, in J. Strachey (Ed), Jokes and their relation to the unconscious (New York, New York: Norton \& Company, 1960).

[6] C. Hempelmann,. The laughter of the 192 Tanganyika epidemic. Humour:International Journal of Humour Research 20(1), 2007, 49-71.

[7] N. Norrick, A theory of humor in interaction. Journal of Literary Theory, 3(2), 2009, 261-284.

[8] M. Billig, Freud and the language of humour, The Psychologist, 15(9), 2002, 452-455.

[9] S. Shehata, Politics of laughter: Nasser, Sadat, and Mubarak in Egyptian political jokes. Folklore, $103.1992,75-91$.

[10] N. Force, The hidden power of jokes. World of Psychology, 2010. Retrieved from http://www.psychcentral.com/blog/archives/2010/.../the-hidden-power-of-humor 
[11] I. Fathi, Kumidya al-hukm al-sumuliyy [The comedy of totalitarian regimes]. (Cairo: General Egyptian Book organisation, 1991).

[12] S. Kanaana, Palestinian humour during the Gulf War. Journal of Folklore Research, 32(1), 1995, 65-75.

[13] R. Provine, The science of laughter. Psychology Today, 33(6). 2000, 58-62.

[14] K. Lorenz, On aggression (Routledge, 2002).

[15] M. Billig, Laughter and Ridicule: Towards a Social Critique of Humour ( London: Sage, 2005).

[16] M. Badarneh, Carnivalesque politics: A Bakhtinian case study of contemporary Arab political humour. Humor: International Journal of Humor Research, 24(3). 2011, 305-327.

[17] H. Salem \& T. Kantaro, in S. Mehrez (Ed.), Translating Egypt's revolution: The language of Tahrir (The American University in Cairo Press, 2012) 183-211.

[18] S. Harutyunyan, Humour: Egypt's revolutionary ally. Prospect Journal of International Affairs at UCSD. 2012. Retrieved from http://prospectjournal.org/2012/07/30/humor-egypts-revolutionary-ally-2

[19] S. Attardo \& V. Raskin, Script theory revis(it)ed: joke similarity and joke representation model. Humor: International Journal of Humor Research, 4(3/4), 1991, 293-347.

[20] A. Krikmann, Contemporary linguistic theories of humour. Folklore, 33. 2006, $27-58$.

[21] C. Hempelmann, \& R. Willibald, 3 WD meets GTVH: Breaking the ground for interdisciplinary humor research. Humor: International Journal of Humour Research 18(4), 2005, 353-388.

[22] S. Attardo, Humorous texts: A semantic and pragmatic analysis (New York: Mouton de Gruyter, 2001).

[23] M. Mulder \& A. Nijholt, Humour Research: State of the Art (Centre for Telematics and Information Technology, University of Twente, 2002).

[24] C. Gruner, The game of humor: A comprehensive theory of why we laugh. (Transaction Publisher, 2001).

[25] D. Oaks, Creating structural ambiguities in humor: Getting English grammar to cooperate. Humor: International journal of humor Research, 7(4), 1994, 377- 401.

[26] A. Berger, An anatomy of humor (New Brunswick, NJ: Transaction Publishers, 1998)

[27] R. Mihalcea. \& S. Pulman, Characterizing humour: An exploration of features in humorous texts. Computational Linguistics and Intelligent Text, Proc. $8^{\text {th }}$ International Conference, CICLing, Mexico City, Mexico. 2007, 337- 347.

[28] R. Bassiouney, Arabic sociolinguistics: Topics in diglossia, gender, identity, and politics ( Georgetown University Press, 2009) 